\title{
Improving Healthcare Access Among the Newly Decarcerated
}

\section{E. Rosalie Li-Rodenborn ${ }^{1^{*}}$, Bernat Navarro-Serer ${ }^{2 *}$, Stephanie Pitts ${ }^{3 *}$, Kavya Anchuri ${ }^{*}$}

${ }^{1}$ Johns Hopkins Bloomberg School of Public Health, Department of Biochemistry \& Molecular Biology, Baltimore, MD

2Johns Hopkins University School of Medicine, Department of Pathology, Baltimore, MD

3Johns Hopkins University School of Medicine, Department of Radiation Oncology and Molecular Radiation Sciences, Baltimore, MD

4Johns Hopkins Bloomberg School of Public Health, Department of Mental Health, Baltimore, MD

*All authors contributed equally

http://doi.org/10.38126/JSPG170209

Corresponding author: bnavarr1@jh.edu

Keywords: Medicaid; opioid crisis; healthcare; insurance; prison system; Maryland

Executive Summary: The American opioid crisis has disproportionately affected our incarcerated population. Approximately two-thirds of inmates nationwide struggle with substance use disorders (Maryland Department of Health 2018; Cohn 2019). Though some receive treatment during incarceration, about $60 \%$ leave prison uninsured (Maryland Department of Health 2018). Without insurance, continuing treatment becomes improbable, significantly increasing the risk of overdosing in the two weeks following decarceration (Binswanger et al. 2007). The State of Maryland has addressed this problem by expanding Medicaid coverage under the Affordable Care Act in 2014. Today, an estimated 90\% of Maryland prisoners qualify for Medicaid upon release (Hancock 2016). Despite Medicaid expansion and other measures, including a 2016 presumptive eligibility policy, most inmates still leave prison unable to access the healthcare for which they qualify (Cohn 2019). This memorandum highlights policy options that ensure eligible inmates leave with unencumbered access to healthcare. We recommend using Presumptive Eligibility to enroll all qualified inmates, which prevents a coverage lapse immediately following release, with implementation of full coverage for all state correctional facilities as the long-term goal.

\section{Background}

Since the eruption of the opioid epidemic in the 1990s, three distinct waves of overdose deaths have swept through the United States. Rampant fentanyl use, along with other opioids, led the HHS to declare a public health emergency in 2017 (Centers for Disease Control and Prevention 2017). Media coverage and policy responses have framed the crisis as manifesting in predominantly white, rural areas. However, urban Black communitiesfor example, in the city of Baltimore, Marylandhave suffered similarly.
The Centers for Disease Control and Prevention have reported that Baltimore City saw 85.2 overdose deaths per 100,000 people in the year 2017 (four times more than in 2011), making Baltimore the city with the highest overdose fatality rate in the US (Baltimore City Health Department 2018). As the number of opioidrelated deaths in Baltimore continues to climb (Hogan and Rutherford 2019), incarcerated individuals have emerged as a particularly vulnerable population.

In the United States, an estimated $65 \%$ of those who are incarcerated have an active substance use 
disorder (National Institute on Drug Abuse 2019). The risk of fatal overdose among inmates experiencing opioid addiction is greatest during the two-week period following their release from prison (Binswanger et al. 2007). These inmates are about $30 \%$ more likely to die from an overdose during this time when compared to the general population (Binswanger et al. 2007; Merrall et al. 2010). This finding highlights that treatment free from interruption is essential. After Maryland expanded Medicaid under the Affordable Care Act in $2014,90 \%$ of inmates qualified for treatment upon release; however, approximately $60 \%$ of former inmates lacked health insurance at eight to ten months post-release (Maryland Department of Health 2018; Hancock 2016). Medicaid enrollment of individuals during incarceration provides an opportunity to improve outcomes and prevent deaths.

\section{Current policy and challenges}

Following the establishment of the Center for Medicare and Medicaid Services (CMS), an exclusion clause prohibited states from billing Medicaid for most inmate care (Fiscella et al. 2017). This exclusion especially harms the newly released demographic by disrupting their care and leading to relapse. Moreover, many states suspend Medicaid coverage upon entry, creating gaps in coverage after prison release. Additionally, most prisons do not offer opioid use treatment, leading to the termination of any existing treatment upon admission (Fiscella et al. 2017; Wakeman and Rich 2015). The limited number of staff and minimal addiction treatment education programs exacerbate the issue (Cohn 2019; Hancock 2016; Fiscella et al. 2017).

For those entering prison with Medicaid insurance after 2005, Maryland authorized coverage suspensions, as opposed to termination (Maryland Department of Health 2018). Additionally, a recent bill approved by the Maryland State legislature now requires local correctional facilities to provide medication-assisted treatment to affected inmates, after initial assessments. Successful implementation of this bill stands to significantly increase the likelihood of sustained recovery. Furthermore, that much of the prison population in Maryland qualifies for Medicaid coverage upon decarceration, as per the 2014 coverage expansion, is conducive to a safe transition to their new lives (Maryland Department of Health 2018; Hancock 2016)

While it may be useful for those entering prison with Medicaid insurance that their coverage is suspended rather than terminated, many individuals entering Baltimore prisons lack insurance of any kind. The CMS-approved Inmate Presumptive Eligibility Program in Maryland allows correctional facilities to determine Presumptive Eligibility (PE), a program conferring full Medicaid coverage to newly released inmates for 60 days after discharge. The 60-day period grants them the time necessary to officially enroll in Medicaid and prevents loss of coverage (Maryland Department of Health 2018; Moyer and Neall 2019).

Though the evidence indicates the cruciality of PE to maintaining inmate recovery, Maryland correctional facilities have yet to enroll a single person in Presumptive Eligibility. In fact, inmates may only apply after a Medicaid application rejection (Moyer and Neall 2019). Select facilities have enrolled a small minority of prisoners in Medicaid, but the majority face too many obstacles to obtain coverage, such as not being offered a chance to enroll or not knowing how to sign up on their own (Cohn 2019). Others serve brief sentences, hours or days, that preclude the possibility of completing enrollment requirements (Cohn 2019).

\section{Policy options}

i. Option 1: Separate presumptive eligibility from the full Medicaid application process.

We propose establishing PE as a primary source of coverage for short-stay individuals and inmates without the necessary paperwork for a formal Medicaid application. Consideration for PE eligibility currently hinges upon an inmate's ability to submit a full Medicaid application, and inmates may only apply after their Medicaid application has been rejected (Moyer and Neall 2019). Most correctional facilities in Maryland instead opt to enroll inmates into full Medicaid, shifting Medicaid PE to a back-up option that most cannot access (Cohn 2019). 


\section{Advantages}

- The ability to enroll inmates into Medicaid PE grants them full coverage for the first two months after release, the time period during which risk for overdose is highest (Binswanger et al. 2007).

- The Medicaid PE program has already been approved by the Department of Health and CMS. For those enrolled, there is an outline ensuring those individuals can successfully enroll in full Medicaid coverage before the end of PE (Maryland Department of Health 2018).

- Establishing PE as the primary option for Medicaid enrollment would prevent cases where a Medicaid application is approved, but the inmate leaves before receiving a Medicaid card.

\section{Disadvantages}

- PE enrollment depends on self-attestation, with no additional documentation needed (Maryland Department of Health 2018). Thus, making enrollment more accessible could lead to a change in the enrollment process, requiring certain documentation.

- The ability to enroll more people in Medicaid under PE may depend upon employees in resource-scarce correctional facilities. The process may require accredited training and new personnel.

- Increased enrollment increases the state's Medicaid expenditures initially, though it will likely reduce costs over time by reducing the treatment lapses that incur high costs to society.

ii. Option 2: Establish Medicaid enrollment programs within correctional facilities.

Preemptively enrolling inmates in Medicaid allows them to leave with coverage, thus permitting continued treatment and overcoming the struggle to self-enroll (Hancock 2016). Over 64 formal Medicaid enrollment programs have been established in American state and local correctional facilities (Johns Hopkins Bloomberg School of Public Health 2015). For example, Ohio's Medicaid Pre-Release Enrollment Program (MPRE) starts 90 days before exit with a class taught by peer Medicaid educators. Interested parties select among five Medicaid plans and complete enrollment prior to release. Prisoners with serious health conditions receive additional resources and help with forming a post-release plan (Jannetta et al. 2017; Guyer et al. 2019). Unfortunately, Maryland has no such program. The Maryland Department of Public Safety and Correctional Services (DPSCS) provides application information, but officials only enroll $12 \%$ of the incarcerated population in Medicaid (Maryland Department of Health 2018; Cohn 2019). We propose the Maryland Department of Health collaborate with the Maryland DPSCS to establish a program similar to Ohio's MRPE.

\section{Advantages}

- A formal program guides inmates through the enrollment process, helping them finish the necessary paperwork, obtain a Medicaid card, and plan post-release care.

- The program has the potential for effective mitigation. This was demonstrated by Ohio's MPRE, which helped $50 \%$ of those without serious conditions and $100 \%$ of those with serious conditions with treatment-associated planning post-release (The Ohio Department of Medicaid 2018).

- Such plans have proven effective in increasing access to treatment. A third of Ohio MRPE participants received substance use treatment after release, and $87.6 \%$ of those treated reported that "Medicaid made it easier for them to get treatment" (The Ohio Department of Medicaid 2018).

\section{Disadvantages}

- The costly initial investment may burden the state. Staff and resources in the Maryland incarceration system are limited (Hancock 2016). Implementing a pre-release enrollment program requires more staff and internet access for enrollment.

- The time needed to complete the enrollment process must be considered. Some prisoners leave within hours to days, precluding them from completing the enrollment process (Cohn 2019). 
iii. Option 3: Inaction

Maintain the current program structure--that is, a small minority of inmates enroll successfully in Medicaid, while most others are not given the opportunity to take advantage of PE. Local correctional facilities are planning to provide medication-assisted treatment and counseling to inmates experiencing addiction by 2023 (Donovan 2019). Additionally, the state plans to establish a treatment center within a Baltimore correctional facility (Donovan 2019). These actions may in turn increase the enrollment of inmates to Medicaid or facilitate the institution of enrollment programs.

\section{Advantages}

- Medicaid fully covers the few inmates who manage to enroll successfully, allowing them to avoid the temporary PE period.

- Maintaining the current Medicaid enrollment program structure would not require any additional money or resources.

\section{Disadvantages}

- Maryland officials currently only enroll around $12 \%$ of the incarcerated population in Medicaid (Cohn 2019). The many uninsured, newly decarcerated people may discontinue treatment, resulting in preventable deaths.

- Inmates serving short sentences (days to weeks) either have their coverage suspended, in case they already have Medicaid coverage, or might not be given the time or opportunity to enroll in Medicaid prior to incarceration release, thus potentially contributing to preventable deaths.

\section{Fiscal analysis}

Annual US spending for illicit drug-related offenses has exceeded \$193 billion (Office of National Drug Control Policy 2012; National Drug Intelligence Center 2011). Expenses flow from the required law enforcement interventions, healthcare costs, and intangible losses derived from negative effects on families and communities. For every dollar invested in treatment and its continuity, decisionmakers see $\$ 11$ return (Ettner et al. 2006). Fiscal analysis indicates that under current policies significantly more is spent than with alternatives, especially in the long term. Treated individuals cost much less over time and return to prison at lower rates, but without Medicaid, treatment is beyond their reach.

- A pilot program saved \$398 per month for each resident treated (Ettner et al. 2006). Participants committed fewer felonies, further reducing costs and increasing the communitylevel quality of life (Estee and Nordlund 2003).

- An analysis of costs to employers found that 60 days of treatment saved employers $\$ 8200$ annually (Jordan et al. 2008). Employers should be considered as potential stakeholders.

- The preponderance of evidence shows that increased access benefits the individual and society (Office of National Drug Control Policy 2012) and enrolled persons report that coverage enabled them to maintain employment and care for their families (The Ohio Department of Medicaid 2018).

- Money saved could be reinvested in the path to recovery (The Ohio Department of Medicaid 2018).

\section{Policy recommendations}

We recommend Option 1 . The recommendation designates Medicaid Presumptive Eligibility as the default means by which inmates obtain coverage and allows for increased enrollment and continued treatment. We recognize establishing Medicaid coverage before leaving prison as the linchpin in achieving several desirable outcomes, including sustained recovery. Our team recommends working toward Option 2 as a longer-term goal, possibly requiring correctional facilities to enroll all eligible inmates by a certain date. The magnitudes of cost reduction achieved in several locations suggest an initial investment stands to reduce spending, improve post-release outcomes, reduce law enforcement demands and associatedhealthcare costs, and provide intangible benefits that flow from stable families and healthy, productive members of society. 


\section{References}

Baltimore City Health Department. 2018. "Baltimore City's Response to the Opioid Epidemic." https://health.baltimorecity.gov/opioidoverdose/baltimore-city-overdose-preventionand-response-information

Binswanger, Ingrid A., Marc F. Stern, Richard A. Deyo, Patrick J. Heagerty, Allen Cheadle, Joann G. Elmore, and Thomas D. Koepsell. 2007. "Release from prison-a high risk of death for former inmates." New England Journal of Medicine 356(2):

157-165.

https://doi.org/10.1056/nejmsa064115

Centers for Disease Control and Prevention 2017. Understanding the epidemic. Centers for disease control and prevention. https://www.cdc.gov/drugoverdose/epidemic L?utm source=EWSE+July $+2017+$ Newsletter\& utm campaign=EWSE + Jul $+2017 \&$ utm medium =email

Cohn, Meredith. 2019. "Maryland Made a Plan to Help People Leaving Prison Get Drug Treatment - but It Never Used It." The Washington Post. March 11, 2019.

https://www.washingtonpost.com/local/mary land-made-a-plan-to-help-people-leavingprison-get-drug-treatment--but-it-never-usedit/2019/03/11/93ae2f30-3f61-11e9-922c64d6b7840b82 story.html

Donovan, Doug. 2019. "Maryland Legislature Approves Bill to Expand Use of Medicines for Addiction Treatment in Jails." baltimoresun.com. Baltimore Sun. June 29, 2019. https://www.baltimoresun.com/politics/bsmd-addiction-treatment-prison-20190405story.html

Estee, Sharon L., and Daniel J. Nordlund. Washington State Supplemental Security Income (SSI) cost offset pilot project: 2002 progress report. Washington State Department of Social and Health Services, Management Services Administration, Research and Data Analysis Division, 2003. https://www.dshs.wa.gov/ffa/rda/researchreports/washington-state-supplementalsecurity-income-ssi-cost-offset-pilot-project-0

Ettner, Susan L., David Huang, Elizabeth Evans, Danielle Rose Ash, Mary Hardy, Mickel Jourabchi, and Yih-Ing Hser. "Benefit-cost in the California treatment outcome project: does substance abuse treatment "pay for itself"?." Health Services Research 41, no. 1 (2006): 192-213. https://doi.org/10.1111/j.1475$\underline{6773.2005 .00466 . x}$
Fiscella, Kevin, Leo Beletsky, and Sarah E. Wakeman. 2017. "The inmate exception and reform of correctional health care." American journal of public health 107(3): 384. https://doi.org/10.2105/AJPH.2016.303626

Guyer, Jocelyn, Kinda Serafi, Deborah Bachrach, and Alixandra Gould. 2019. "State strategies for establishing connections to health care for justice-involved populations: the central role of Medicaid." New York Commonwealth Fund. https://www.commonwealthfund.org/publica tions/issue-briefs/2019/jan/state-strategieshealth-care-justice-involved-role-medicaid

Hancock, Jay. 2016. "Thousands Leave Maryland Prisons With Health Problems And No Coverage." NPR. April 24, 2016. https://www.npr.org/sections/healthshots/2016/04/24/475271336/thousandsleave-maryland-prisons-with-healthproblems-and-no-coverage?t=1595253458688

Hogan, Larry, and Governor-Boyd Rutherford. 2019. "Drug-and alcohol-related intoxication deaths in Maryland, 2019 Q3." https://health.baltimorecity.gov/opioidoverdose/

https://www.justice.gov/archive/ndic/pubs4 4/44731/44731p.pdf

Jannetta, Jesse, Jane B. Wishner, Rebecca Peters, Justice Policy Center, and Health Policy Center (Urban Institute). Ohio's Medicaid Pre-Release Enrollment Program. Urban Institute. https://www.urban.org/sites/default/files/pu blication/88051/ohio medicaid 1.pdf

Johns Hopkins Bloomberg School of Public Health. State and Local Initiatives to Enroll Individuals in Medicaid in Criminal Justice Settings, 2015. Johns Hopkins Bloomberg School of Public Health.

https://www.jhsph.edu/research/centersand-institutes/center-for-mental-health-andaddiction-policyresearch/research/economics-and-servicesresearch/arnold-foundation-project-map/

Jordan, Neil, Grant Grissom, Gregory Alonzo, Laura Dietzen, and Scott Sangsland. 2008. "Economic benefit of chemical dependency treatment to employers." Journal of Substance Abuse Treatment 34(3):311-319.

Maryland Department of Health. (2018). "Report on Connecting Individuals Who Are Transitioning from the Criminal Justice System to Health Care." Maryland Department of Health. https://mmcp.health.maryland.gov/Document s/ICRs/2017/inmatepresumptiveeligibility]CR final11-17.pdf 
Merrall, Elizabeth LC, Azar Kariminia, Ingrid A. Binswanger, Michael S. Hobbs, Michael Farrell, John Marsden, Sharon J. Hutchinson, and Sheila M. Bird. 2010. "Meta-analysis of drug-related deaths soon after release from prison." Addiction 105(9):1545-1554. https://doi.org/10.1111/j.13600443.2010.02990.x

Moyer, Stephen T. and Robert R. Neall. "Hogan Administration Officials: Maryland Prisoners Are Getting on Medicaid." Baltimore Sun. June 2, 2019.

https://www.baltimoresun.com/opinion/read ers-respond/bs-ed-rr-maryland-prisonersmedicaid-letter-20190319-story.html

National Drug Intelligence Center. 2011. "The Economic Impact of Illicit Drug Use on American Society." United States Department of Justice. https://www.justice.gov/archive/ndic/pubs4 4/44731/44731p.pdf

National Institute on Drug Abuse. 2019. "Criminal Justice DrugFacts." National Institute on Drug Abuse.

https://www.drugabuse.gov/publications/dru gfacts/criminal-justice
Office of National Drug Control Policy. 2012. Cost Benefits of Investing Early in Substance Abuse Treatment. Office of National Drug Control Policy.

https://obamawhitehouse.archives.gov/sites/ default/files/ondcp/Fact Sheets/investing in treatment 5-23-12.pdf

The Ohio Department of Medicaid. 2018. "2018 Ohio Medicaid Released Enrollees Study." The Ohio Department of Medicaid. https://medicaid.ohio.gov/reports

Wakeman, Sarah E., and Josiah D. Rich. 2015. "Addiction treatment within US correctional facilities: bridging the gap between current practice and evidence-based care." Journal of addictive diseases. 34(2-3):220-225. https://doi.org/10.1080/10550887.2015.105 $\underline{9217}$

E. Rosalie Li-Rodenborn is a second-year graduate student studying public health biology at The Johns Hopkins Bloomberg School of Public Health. Her interest exists in the space where science meets policy, and she hopes to change the way scientists approach public engagement. Her publication NOVEL SCIENCE helps scientists learn to communicate with lay audiences while producing content that prioritizes excellence in writing, scientific rigor, and aesthetic. She hopes to pursue a Ph.D.

Bernat Navarro-Serer is a third-year Ph.D. Candidate studying pancreatic cancer at The Johns Hopkins University School of Medicine. He studies mechanisms of invasion in pancreatic ductal adenocarcinoma using 3D organoid models from human derived tumors. He is the Social Media Chair at the Johns Hopkins Science Policy Group and the Eastern Hub Co-Chair at the National Science Policy Network.

Stephanie Pitts is a third-year Ph.D. candidate in Cellular and Molecular Medicine at the Johns Hopkins University School of Medicine. Her research focuses on targeting RNA polymerase I as an anti-cancer therapeutic strategy. She holds a B.A. in Biology from Brown University.

Kavya Anchuri is a second-year MD candidate at the University of Calgary's Cumming School of Medicine in Alberta, Canada. She completed a Master of Health Science at the Johns Hopkins Bloomberg School of Public Health in 2018, where she published her thesis research on the epidemiology of suicide among emerging adults in the U.S. After this, she worked for the Nova Scotia Health Authority in Atlantic Canada to evaluate transitions-of-care between pediatric to adult mental health services in the region.

\section{Acknowledgements}

The authors wish to thank the Johns Hopkins Science Policy Group in the preparation of this manuscript. 